Revue d'histoire du XIXe siècle

Société d'histoire de la révolution de 1848 et des

révolutions du XIXe siècle

$52 \mid 2016$

Chrononymes. Dénommer le siècle

\title{
Frank PROCHASKA. Eminent Victorians on American Democracy. The View from Albion
}

Oxford University Press, 2012

\section{Valentine Brunet}

\author{
CpenEdition \\ Journals \\ Édition électronique \\ URL : http://journals.openedition.org/rh19/5014 \\ DOI : 10.4000/rh19.5014 \\ ISSN : 1777-5329 \\ Éditeur \\ La Société de 1848 \\ Édition imprimée \\ Date de publication : 1 juin 2016 \\ Pagination : 202-204 \\ ISSN : 1265-1354 \\ Référence électronique \\ Valentine Brunet, «Frank PROCHASKA. Eminent Victorians on American Democracy. The View from \\ Albion », Revue d'histoire du XIXe siècle [En ligne], 52 | 2016, mis en ligne le 01 juin 2016, consulté le 25 \\ septembre 2020. URL : http://journals.openedition.org/rh19/5014; DOI : https://doi.org/10.4000/ \\ rh19.5014
}

Ce document a été généré automatiquement le 25 septembre 2020.

Tous droits réservés 


\title{
Frank PROCHASKA. Eminent Victorians on American Democracy. The View from Albion
}

\author{
Oxford University Press, 2012
}

\section{Valentine Brunet}

\section{RÉFÉRENCE}

Frank PROCHASKA. Eminent Victorians on American Democracy. The View from Albion, Oxford University Press, 2012, 192 p. 34,20 euros.

1 Historien spécialiste des relations anglo-américaines, Frank Prochaska s’intéresse aux interprétations de la démocratie américaine dans les œuvres de quatre figures britanniques du XIX ${ }^{\mathrm{e}}$ siècle : John Stuart Mill, Walter Bagehot, Henry Maine et James Bryce. Dans ce livre, il restitue la fascination mêlée d'inquiétude des intellectuels victoriens face aux tumultes de la vie politique démocratique. Peu de penseurs sont alors prêts à envisager une évolution des institutions britanniques sur le modèle américain. Les auteurs choisis sont donc assez représentatifs de l'esprit du temps, et ouvrent diverses pistes de réflexion critique. John Stuart Mill est l'un des philosophes majeurs de l'ère victorienne, théoricien du libéralisme utilitariste. Quant à Walter Bagehot, il façonne l'opinion des classes moyennes à travers ses responsabilités éditoriales au journal The Economist. Libéral modéré, Bagehot est influencé par le courant « évolutionniste ", tout comme le conservateur Henry Maine, qui lui donnera ses lettres de noblesse dans le champ de l'histoire du droit, avec son ouvrage Ancient Law (1861). Plus favorable à la démocratie, James Bryce est l'auteur de The American Commonwealth (1888) et de nombreux articles sur la politique américaine.

2 Frank Prochaska expose avec clarté les espoirs et les craintes de ces intellectuels dans une Grande-Bretagne en voie de démocratisation. S'il mentionne l'importance de Tocqueville et De la démocratie en Amérique (1835-1840) dans la lecture que font ces 
différents penseurs du système américain, il note aussi leur tendance à voir cette démocratie comme un développement particulier d'institutions ancrées dans la culture juridique britannique. Loin d'être radicalement novatrice, la démocratie américaine serait le fruit d'une adaptation des mœurs parlementaires britanniques au contexte socio-historique qui prévalait de l'autre côté de l'Atlantique. Si l'Amérique ne diffère pas profondément de la "société-mère », elle peut offrir des indications précieuses sur l'avenir du modèle politique britannique. Ce présupposé amène les quatre figures étudiées à mettre l'accent sur les continuités plutôt que sur les ruptures : l'exceptionnalisme américain relève, selon eux, du mythe. Or, certains aspects de la vie politique outre-Atlantique inquiètent les intellectuels victoriens. Ainsi en est-il de l'égalitarisme et des discours démagogiques des représentants américains. Le Sénat apparaît, à cet égard, comme une exception, unanimement saluée par les quatre penseurs. À long terme, John Stuart Mill, pourtant admiratif de l'indépendance et de l'esprit civique des Américains, craint que l'absence d'une véritable élite intellectuelle ne mette la démocratie en danger. Quant aux trois autres penseurs, ils sont plus intéressés par le fonctionnement de la Constitution américaine en tant que frein conservateur aux emballements de l'opinion publique majoritaire. Henry Maine, qui ne cache pas son rejet de la démocratie, loue néanmoins la stabilité qu'offre une Constitution écrite datant du XVIII ${ }^{\mathrm{e}}$ siècle, peu susceptible d'être amendée en raison d'une procédure de révision complexe. Walter Bagehot pointe les inconvénients d'un tel système et vante la supériorité de la tradition britannique non écrite, plus malléable en cas de crise politique. F. Prochaska suggère que la rigidité de la Constitution américaine, conjuguée à une stricte séparation des pouvoirs, est responsable des impasses et des conflits qui caractérisent le système politique américain.

3 Parmi les penseurs abordés, John Stuart Mill et James Bryce sont les plus favorables à la démocratie, tandis que Walter Bagehot et Henry Maine se montrent très critiques. Tous partagent néanmoins la même crainte de la montée des masses, et cherchent les moyens de l'encadrer ou de la ralentir, alors que les réformes électorales se succèdent en Grande-Bretagne au cours du XIX siècle. Comment préserver les qualités intellectuelles et morales de l'élite politique avec un électorat élargi aux classes peu éduquées ? Comme Tocqueville, Mill évoque le danger d'une «tyrannie de la majorité ", et souligne la puissance du conformisme aux États-Unis. Bagehot et Maine sont encore plus réservés et prédisent la catastrophe, surtout après le Reform Act de 1867, élargissant le corps électoral en Grande-Bretagne au bénéfice des habitants des villes. James Bryce reste serein face à cette démocratisation en marche. Toutefois, écrivant dans les années 1880 , il observe le rôle croissant de l'argent et des partis dans la vie politique américaine. La corruption et l'esprit partisan pourraient menacer la jeune démocratie au tournant du siècle. Son enthousiasme repose davantage sur l'esprit d'entreprise et l'indépendance de la plupart des citoyens américains vis-à-vis d'une vie politique qu'il juge décevante. Cette analyse l'éloigne clairement de la position de Tocqueville sur l'esprit civique des Américains. Le livre de Frank Prochaska offre ainsi un point de vue comparatif particulièrement instructif, mettant en lumière les différences d'approches entre le penseur politique français le plus réputé des années 1830-1840 et ses homologues victoriens, qui, à l'exception de Mill, demeurent sceptiques face à la prospective un peu abstraite de la Démocratie en Amérique. Bagehot et Bryce revendiquent leur empirisme, tandis que Maine s'appuie sur l'évolution des textes de droit, avec un souci de la longue durée. 
4 Ce livre concis et agréable à lire constitue une bonne introduction aux idées des intellectuels victoriens sur la démocratie américaine, sans prétendre traiter tous les aspects de leur pensée politique. Cet ouvrage devrait encourager à redécouvrir les textes de ces grandes figures britanniques, qui restent riches d'enseignements pour l'histoire de l'idée démocratique. 